\title{
Outcome of Early Laparoscopic Cholecystectomy in Acute Calculus Cholecystitis
}

\author{
Mohammed Masudur Rahman'1, Kamrunnahar², Shimul Akter ${ }^{3}$, \\ AZM Shakhawat Hossain ${ }^{4}$, Fouzia Mujib Un Naz
}

${ }^{1}$ Assistant Professor, Sir Salimullah Medical College and Mitford Hospital, Dhaka, Bangladesh; ${ }^{2}$ Junior Consultant (Gynae and Obs.), OSD, DGHS. Attached to President's Office, Bangabhaban, Dhaka, Bangladesh; ${ }^{3}$ Assistant Professor, Department of Gynaecology \& Obstetrics, Monowara Sikder Medical College, Shariatepur, Bangladesh; ${ }^{4}$ Professor and Principal, Department of Surgery,

Bangladesh Medical College, Dhaka, Bangladesh; ${ }^{5}$ Assistant Professor, Department of Radiology \& Imaging, Dhaka Dental College, Dhaka, Bangladesh

[Received: 12 April 2019; Accepted: 20 May 2019; Published: 1 July 2019]

\begin{abstract}
Background: : The surgical management of patients presenting with acute calculus cholecystitis remains controversial. Objective: The aim of this study was to evaluate the safety and feasibility of early laparoscopic cholecystectomy for acute calculus cholecystitis and to document the outcome of early laparoscopic cholecystectomy. Methodology: This observational comparative study was carried out in the Department of General Surgery of Sylhet MAG Osmani Medical College Hospital, Sylhet from July 2006 to June 2008, a period of 24 months. The study group enrolled 101 patients of both sexes who underwent laparoscopic cholecystectomy surgery and divided into two groups. 51 patients with a diagnosis of acute calculus cholecystitis were assigned randomly to early laparoscopic cholecystectomy within $72 \mathrm{~h}$ of admission (early group, $\mathrm{n}=51$ ) or to initial conservative treatment followed by elective laparoscopic cholecystectomy, 6 to 12 weeks later (elective group, $n=50$ ). Results: There was no significant difference in operation times (early, 81.98 vs elective, 79.96), conversion rates (early, $5.88 \%$ vs elective $10 \%$ ) or postoperative complications (early $31,4 \%$ vs elective, $24 \%$ ).However, during early laparoscopic cholecystectomy distended gallbladder containing infected bile was more in 41 patients $(80.01 \%)$ while 04 patients $(09 \%)$ and 03 patients $(7.20 \%)$ in elective laparoscopic cholecystectomy ( $>0.05)$ and significantly $(\mathrm{p}<0.05)$ more modification in operative techniques in early group than elective group. In addition, early group had shorte hospital stay ( 8.37 vs 12.62 days0 and lower treatment cost (5243.13 vs 7327) which were statistically significant $(p<0.05)$. Conclusion: In conclusion laparoscopic cholecystectomy during the early admission with acute calculus cholecystitis can be performed safely and successfully. Earlier surgery has a beneficial impact for patients and the National Health Service. [Journal of National Institute of Neurosciences Bangladesh, 2019;5(2):161-166]
\end{abstract}

Keywords: Acute calculus cholecystitis; early laparoscopic cholecystectomy; elective lapaoscopic cholecystectomy

Correspondence: Dr. Mohammed Masudur Rahman, Assistant Professor, Department of Surgery, Sir Salimullah Medical College, Dhaka, Bangladesh; Cell no.: +8801711960474; Email: masud1971rahman@gmail.com

Conflict of interest: There is no conflict of interest relevant to this paper to disclose.

Funding agency: This research project was not funded by any group or any institution.

Contribution to authors: Rahman MM, Kamrunnahar contributed from the protocol preparation, data collection, statistical analysis up to report writing. Manuscript writing was performed by Kamrunnahar, Akter S. Hossain AZMS, FMU Naz involved in supervision of the research work and revision of manuscript.

How to cite this article: Rahman MM, Kamrunnahar, Akter S, Hossain AZMS, FMU Naz. Outcome of Early Laparoscopic Cholecystectomy in Acute Calculus Cholecystitis. J Natl Inst Neurosci Bangladesh, 2019;5(2): 161-166

Copyright: (C2019. Rahman et al. Published by Journal of National Institute of Neurosciences Bangladesh. This article is published under the Creative Commons CC BY-NC License (https://creativecommons.org/licenses/by-nc/4.0/). This license permits use, distribution and reproduction in any medium, provided the original work is properly cited, and is not used for commercial purposes.

\section{Introduction}

Cholelithiasis is the most common billiary pathology in surgical unit. It occurs in at least $20.0 \%$ of women over age of forty years. Incidence of gall stone in male is about $1 / 3$ of female and increases with age. So that, between 50 and 65 years of age about $20.0 \%$ of female and $5.0 \%$ of male is affected ${ }^{1}$. When such asymptomatic patient followed, between $1.0 \%$ and $4.0 \%$ per year developed biliary symptoms ${ }^{2}$. Therefore, cholecystectomy is the commonest operation in elective abdominal surgery.

Acute cholecystitis was defined by three criteria: Acute 
abdominal pain commonly in right subcostal or in midline epigastric area with duration more than 12 hours, fever and leucocytosis. Acute cholecystitis was then confirmed by the presence of gall bladder stone and signs of inflammation on ultrasonography and clinical biochemistry data ${ }^{3}$. The traditional management of acute cholecystitis is initial conservative treatment with antibiotic followed by elective cholystectomy usually after 6 to 8 weeks when inflammatory condition subsided. In this study it was defined as elective or delayed cholecystectomy. Some surgeons advocate urgent operation as a routine measure in case of acute condition, that operation is undertaken with in 48 to 72 hours of onset of attack when excellent surgical facilities are available, termed as early cholecystectomy ${ }^{4}$.

The appropriate timing for laparoscopic cholecystectomy in the treatment of acute calculus cholecystitis remains controversial $^{5-7}$. Several randomized studies in the pre-laparoscopic era had shown that early open cholecystectomy for acute calculus cholecystitis was better than elective or delayed open cholecystectomy in terms of shorter hospital stay but both had similar operative mortality and morbidity ${ }^{8-11}$. Initial reports suggested that early laparoscopic surgery for acute calculus cholecystitis was associated with increased complication rates, prolonged operation times and increased conversion rates ${ }^{12}$. As the consequence, initial conservative treatment with subsequent elective laparoscopic surgery became accepted practice ${ }^{12}$. More recently, the application of early laparoscopic surgery for the treatment of acute calculus cholecystitis has become accepted as safe, although conversion rate may be higher $^{12}$.

With increasing experience, introduction of new instruments, now any type of gall bladder can be managed by laparoscopic method. For reduction of complications, various studies are ongoing in different part of the world to find out spectrum of complications of laparoscopic cholecystectomy, their methods of identification, prevention and appropriate measures ${ }^{13}$.

However considering the time required for an accurate pre-operative diagnosis and for arrangement of operating schedule, we define early laparoscopic cholecystectomy as those performed within 72 hours of admission and elective operation those are treated conservatively, discharged and readmitted for surgery after an interval of 6 to 8 weeks.

On the background of these two thoughts of school, this study had been taken up to observe the outcome of early laparoscopic cholecystectomy in acute calculus cholecystitis by using different parameter like operative complications, hospital stay, conversion rate, treatment cost.

\section{Methodology}

Patient selection and study design: This prospective comparative study was conducted in the Department of General Surgery of Sylhet MAG Osmani Medical College Hospital, Sylhet from July 2006 to June 2008, a period of 24 months. After approval from the institutional ethics committee, 101 patients of both sexes admitted for acute calculus cholecystitis were evaluated by clinical examination and investigations. The diagnosis of acute calculus cholecystitis was based on a combination of clinical criteria (acute right upper quadrant tenderness, temperature exceeding $37 \square \mathrm{c}$ and white blood cell count greater than $10 \times 109 / \mathrm{L}$ ) and ultrasonographic criteria (thickened, edematous distended gallbladder, presence of stone in gallbladder, ultrasonic Murphy's sign and pericholicystic fluid collection). Patients with incidental findings of acute inflammation of the gallbladder during another elective surgery, concomitant diseases like CRF, any malignancy, jaundice, uncontrolled DM, HTN, pancreatitis or severely malnutrited patients were excluded from this study. Informed consent was obtained. Included patients were divided into either the "early" group or the "elective" group. In the early group, laparoscopic cholecystectomy was performed within $72 \mathrm{~h}$ of admission (early group, $\mathrm{n}=51$ ), whereas in the elective group, conservative treatment with intravenous fluids and antibiotics was given (elective group, $n=50$ ). They were discharged from hospital after a complete relief of symptoms and were called for laparoscopic cholecystectomy after 6-8 weeks. Data of all patients were collected on a preformed data sheet.

Surgical Technique: The surgery was done with the patient under general anaesthesia using endotracheal intubation. Nasogastric suction catheters and urinary catheters were used if clinically indicated. Initial pneumoperitoneum done usually by open laparoscopic technique, sometimes by blind puncture with a Veress needle through a supraumbilical incision. Four laparoscopic ports were used and local anaesthetics were used in all ports. Two $10-\mathrm{mm}$ ports (one around the umbilical $10-\mathrm{mm}$ port for the optical system and one epigastric port for the clip applicator or suction device) and two 5-mm ports (one at the midclavicular line along the right subcostal margin and one in the right lumber or right iliac fossa) were used. If needed, a fifth port was added to improve exposure for liver extraction. Ports were inserted as per baseball diamond theory. 
Adhesion release and exposure of Calot's triangle were first undertaken. The cystic pedicle was dissected to isolate the cystic duct and the artery separately. Both were then clipped and divided. The gallbladder was dissected off its bed with a monopolar cautery hook or spatula and removed via the epigastric or umbilical port sites. Some modifications needed during surgical procedure for acute calculus cholecystitis. In case of empyema gallbladder decompressive aspiration done by aspirator. For phlegmonous mass in gallbladder dissection done by suction tube, proper traction and counter traction. Blunt dissection needed sometimes done by hard swab. Monopolar diathermy were used for control of minor haemorrage. Sometimes endobag was used to remove specimen if gallbladder is perforated during dissection or stone spillage occurred. All structures identified properly before callot's triangle dissection.

Table 1: Clinical data and laboratory results on admission
Statistical Analysis: Data were expressed as mean and SD. SPSS (statistical Packages for Social Sciences) for windows version 16 was used for data analysis. Unpaired ' $t$ ' test was done and also significant test of categorical variables were performed with chi-square test with $95 \%$ confidence interval to make inference. $\mathrm{p}$ value $<0.05$ was accepted as level of significance.

\section{Results}

During the study period, a total 101 patients were randomized; 51 patients in the early group and 50 patients in the elective group. The two groups were well matched in terms of age and sex, as well as clinical and laboratory findings. (Table 1)

Ultrasonographic findings: The ultrasonographic findings of the patients in the two groups were similar except for significantly $(p<0.001)$ higher proportion of patients with edematous gallbladder in the early group (Table 2).

\begin{tabular}{lccc}
\hline Variables & Early group $(\mathbf{n}=\mathbf{5 1})(\mathbf{M e a n} \pm \mathbf{S D})$ & Elective group $(\mathbf{n}=\mathbf{5 0})(\mathbf{M e a n} \pm \mathbf{S D})$ & p value \\
\hline Age $($ year) & $42.60 \pm 10.41$ & $39.92 \pm 11.57$ & 0.43 \\
Sex (F:M) & $39: 12$ & $46: 4$ & 0.54 \\
Body weight $(\mathrm{kg})$ & $66.78 \pm 8.33$ & $67.48 \pm 8.33$ & 0.43 \\
Previous surgery & 03 & 06 & 0.54 \\
Duration of acute stage (days) & 2.34 & 3.89 & 0.44 \\
Fever $>37.5 \square \mathrm{c}$ & $38.15 \pm 0.86$ & $37.89 \pm 0.74$ & 0.71 \\
WBC (109/L)>10 & $13.36 \pm 3.4$ & $14.36 \pm 10.82$ & 0.09 \\
Total bilirubin (mg/dL) & $1.10 \pm 0.38$ & $1.07 \pm 0.34$ & 0.39 \\
Alkaline phosphatase (IU/L) & $125.54 \pm 24.73$ & $123.42 \pm 22.08$ & 0.07 \\
Previous biliary symptoms & 11 & 08 & 0.10 \\
\hline
\end{tabular}

Table 2: Ultrasonographic Findings on Initial Admission

\begin{tabular}{lccc}
\hline Ultrasonographic findings & Early group(n=51) & Elective group(n=50) & p value \\
\hline Thickened gallbladder Wall & $39(70 \%)$ & $43(66 \%)$ & 0.53 \\
Edematous gallbladder wall & $44(80 \%)$ & $16(45 \%)$ & 0.001 \\
Distended gallbladder & $48(90.02 \%)$ & $34(87.03 \%)$ & 0.10 \\
Presence of gallstones & $51(100 \%)$ & $50(100 \%)$ & 0.89 \\
USG Murphy's sign & $43(85.01 \%)$ & $28(76.22 \%)$ & 0.76 \\
Pericholecystic collection & $07(52.23 \%)$ & $12(55.05 \%)$ & 0.54 \\
Dilated CBD & 00 & $02(3 \%)$ & 0.88 \\
\hline
\end{tabular}

Table 3: Operative findings of the Study Population

\begin{tabular}{lccc}
\hline Operative findings & Early group(n=51) & Elective group(n=50) & p value \\
\hline Severe adhesion & $11(21.57 \%)$ & $23(46 \%)$ & 0.01 \\
Distended gallbladder & $41(80.01 \%)$ & $04(9 \%)$ & 0.001 \\
Pus or turbid bile in gallbladder & $41(80.01 \%)$ & $03(7.20 \%)$ & 0.001 \\
\hline
\end{tabular}


Table 4: Modification of technique in operation

\begin{tabular}{lccc}
\hline Modification of technique & Early group(n=51) & Elective group(n=50) & p value \\
\hline Use of fifth cannula & $3(5.88 \%)$ & $0(0.0 \%)$ & 0.22 \\
Gall bladder decompression & $41(75 \%)$ & $4(8.09 \%)$ & 0.001 \\
Use of ligature for cystic duct & $9(12.09 \%)$ & $7(10.7 \%)$ & 0.45 \\
Enlargement of umbilical incision & $27(40 \%)$ & $13(20.02 \%)$ & 0.01 \\
Use of drainage & $37(70 \%)$ & $16(26.06 \%)$ & 0.001 \\
\hline
\end{tabular}

Table 5: Operative Time and Conversion Rate (Mean \pm SD)

\begin{tabular}{lccc}
\hline Operative time $(\mathbf{m i n})$ & Early group(n=51) & Elective group(n=50) & p value \\
\hline Total operative time & $81.98 \pm 13.95$ & $79.96 \pm 14.81$ & 0.48 \\
Successful laparoscopic procedure & $82.00 \pm 14.02$ & $78.78 \pm$ & 0.17 \\
Conversion rate & $5.88 \%(03)$ & $10 \%(05)$ & 0.45 \\
\hline
\end{tabular}

Operative findings: In early cholecystectomy the gallbladder was significantly $(\mathrm{p}<0.001)$ more distended and filled with mucus, turbid bile or pus than elective cholecystectomy. However, severe adhesion were significantly $(\mathrm{p}<0.01)$ higher among patients in elective group than early group (Table 3 ).

Modification of technique in operation: Significantly $(p<0.001)$ more modification in operation technique including gallbladder decompression, closed drainage in subhepatic space were required in early group. An additional cannula was used for 03 patients in early group to facilitate retraction of viscera (Table 4).

Operative time and conversion rate: The mean operative time for early group was higher than elective group whereas the mean conversion rate for early group was less than elective group. However, this difference did not show significance $(p>0.05)$ on statistical analysis (Table 5).

Postoperative complications: In cholecystectomy operation, post operative complications were noticed in $16(31.4 \%)$ patients in early group compared to 12 (24\%) patients in elective group (Table 6).
Table 6: Postoperative Complications

\begin{tabular}{lcc}
\hline Complications & $\begin{array}{c}\text { Early group } \\
(\mathbf{n}=\mathbf{5 1})\end{array}$ & $\begin{array}{c}\text { Elective } \\
\text { group (n=50) }\end{array}$ \\
\hline Wound infection & 05 & 03 \\
Sub-hepatic collection & 01 & 00 \\
Drainage of bile stained fluid & 05 & 02 \\
Chest infection & 04 & 05 \\
Urinary tract infection & 01 & 02 \\
Obstructive jaundice & 00 & 00 \\
Total & $\mathbf{1 6}(\mathbf{3 1 . 4 \% )}$ & $\mathbf{1 2}(\mathbf{2 4 \% )}$ \\
\hline
\end{tabular}

Hospital stay: Post-operative hospital stay was slightly higher in early group than elective group but it was non-significant $(\mathrm{p}>0.05)$ whereas total hospital stay was significantly higher $(p<0.05)$ in elective group (Table 7).

Treatment cost: Approximate treatment cost by patients estimated which is significantly $(p<0.05)$ lower in early laparoscopic cholecystectomy than elective laparoscopic cholecystectomy (Table 8).

Table 7: Hospital stay (Mean \pm SD)

\begin{tabular}{lccc}
\hline Hospital stay (days) & Early group(n=51) & Elective group(n=50) & p value \\
\hline Postoperative hospital stay & $3.76 \pm 1.63$ & $3.56 \pm 1.58$ & 0.52 \\
Total hospital stay & $8.37 \pm 1.74$ & $12.62 \pm 2.08$ & 0.001 \\
\hline
\end{tabular}

Table 8: Treatment cost $(\mathrm{Mean} \pm \mathrm{SD})$

\begin{tabular}{lccc}
\hline Variable & Early group $(\mathbf{n}=\mathbf{5 1})$ & Elective group(n=50) & p value \\
\hline Amount & $5243.13 \pm 258.46$ & $7327.00 \pm 68$ & 0.001 \\
\hline
\end{tabular}

Unpaired ' $t$ ' test was done to see the group difference. $p$ was significant $(<0.05)$ 


\section{Discussion}

This prospective comparative study was carried out with an aim to compare the outcome of early and elective laparoscopic cholecystectomy in acute calculus cholecystitis. In the early stage, acute calculus cholecystitis was considered a contraindication to laparoscopic cholecystectomy. Currently, it has been shown that laparoscopic cholecystectomy is feasible and safe for acute calculus cholecystitis. Various studies have reported high conversion rates, ranging from $6.5 \%$ to $35.0 \%{ }^{6,14,15}$. However, in some series the diagnosis of acute cholecystitis was made according to either the operative or pathological findings without consideration of clinical condition ${ }^{14}$. Results from these series might not be applicable to patients who have clinical evidence of acute calculus cholecystitis. For evaluation of the rule and timing of laparoscopic cholecystectomy in the management of this clinical problem, only patients with clinical, laboratory and ultrasonic evidence of acute cholecystitis should be included.

The technical difficulty of a laparoscopic cholecystectomy is related to the operative findings. During early laparoscopic cholecystectomy, distended edematous gallbladder containing infected bile was frequently encountered in $41(80.01 \%)$ patients whereas $4(9 \%)$ patients and $3(7.20 \%)$ patients of elective laparoscopic cholecystectomy developed distended gallbladder containing infected bile and this could be overcome by modifications in operative technique including gallbladder decompression, closed drainage in sub-hepatic space. These were required significantly in early group than elective laparoscopic cholecystectomy. These findings were in accordance with the study done by previous study ${ }^{16}$.

The difference in the total operation times in the present study was not significant, although early group patients required a longer operation time than elective group. This finding of the study was consistent with the findings of previous study by Lo et $\mathrm{al}^{4}$.

In current study, $03(5.88 \%)$ patients in the early group patients and $05(10 \%)$ patients in the elective group patients required conversion to open surgery. The most common cause of conversion was difficulty in exposing the gallbladder and dissection because of severe adhesions (one in the early group and three in the elective group). In the immediate phase of inflammation, adhesions are easily separated and there is usually an edematous plane around the gallbladder that facilitates dissection. After a period of conservative treatment, the inflammation and edema are replaced by fibrotic adhesions between the gallbladder and surrounding structures, which occasionally render laparoscopic dissection extremely difficult. Similar pattern of finding was also noted in the study by Lo et $\mathrm{al}^{4}$.

In our study, there were no bile duct injuries or any other major complications compared to open cholecystectomy. Minor complications occurred in $28(27.72 \%)$ of 101 patients, 16 patients in early group and 12 patients in early group. The most common minor complications were wound infection, bile stained fluid drainage.

In this study, total hospital stay after laparoscopic cholecystectomy for acute cholecystitis (6.4 days for early group and 12.2 days for elective group) as reported in the literature. Patients undergoing successful early group have a little longer postoperative hospital stay than do those who have undergone elective surgery but total hospital stay was significantly shorter in the early group. This can be explained by the presence of acute intra-abdominal inflammation before surgery in the early group with resulting delay in the postoperative recovery. Such differences in the postoperative hospital stay between elective groups were unnoticed in the pre-laparoscopic era, because the slower recovery after open surgery determines the duration of postoperative hospital stay. Major advantages of the early laparoscopic cholecystectomy is the reduction of total hospital stay being $(8.37 \pm 1.74$ days vs. $12.62 \pm 2.08)$ and reduce total treatment cost significantly. These findings were on the parallel lines as in previous studies by Lo et $\mathrm{al}^{4}$ and Kolla et $\mathrm{al}^{16}$.

\section{Conclusion}

Initial conservative treatment followed by elective or delayed surgery cannot reduce conversion rate and morbidity of laparoscopic cholecystectomy for acute calculus cholecystitis. Early operation within 72 hours of admission has medical and socioeconomic benefits and both patients and hospital administration. It is also safe and feasible, offering the additional benefit of a shorter hospital stay.

\section{References}

1. Doherty GM. Billiary Tree. In: Laurence WW editor. Current Surgical Diagnosis and Treatment 14th ed. p. 589-590.

2. Russel RCG. The Gall Bladder and Bile Duct. In: Williams NS and Bulstrode CJK editor. Bailey and Love's Short Practice of Surgery. Hodder, A member of hodder headline group; 27th ed. p. 1094-1113.

3. Vetrhus M, Soreide OI, Nesvic, Sondenna K. Acute Cholicystitis; Interval surgery or observation. Randomized clinical trial. Scand J Gastroenterol. 2003; 38: 985-990. 
4. Lo CM, Liu CL, Fan ST, Lai EC, Wong J. Prospective randomized Study of Early Versus Delayed Laparoscopic Cholecystectomy For Acute Cholecystitis. Annals of Surg. 1998; 227: 461-467.

5. Zucker KA, Flowers JL, Bailey RW, et al. Laparoscopic Management of Acute Cholecystitis. Am Journal Surg. 1993; 165: 508-514.

6. Cox MR, Wilson TG, Luck AJ, et al. Laparoscopic cholecystectomy for Acute Inflammation of The Gallbladder. Ann Surg. 1993; 218: 630-634.

7. Bender JS, Zenilman ME. Immediate laparoscopic cholecystectomy as Definitive Therapy for Acute Cholecystitis. Surg Endosc. 1995; 9: 1081-1084.

8. Jarvinen HJ, Hastbacka J . Early Cholecystectomy for Acute Cholecystitis : A Prospective Randomized Study. Ann Surg. 1980;191: 501-505.

9. Lahtinen J, Alhava EM, Aukee S. Acute Cholecystitis Treated by Early and Delayed Surgery: A Controlled Clinical Trial. Scand J Gastrenterol. 1978; 13: 673-678.

10. Norrby S, Herlin P, Holmin T, Sjodhal R, Tagesson C. Early or Delayed Cholecystectomy in Acute Cholecystitis? A Clinical Trial. Br J Surg. 1983; 70: 163-165.
11. McArthur P, Cuschieri A, Sells RA, Shields R. Controlled Clinical Trial Comparing Early with Interval cholecystectomy for Acute Cholecystitis. Br J Surg. 1975; 62: 850- 852.

12. Collet D. Laparoscopic Cholecystectomy in 1994; Results of a Prospective Conducted by SFCERO. Surg Endosc. 1997; 11: 56-63.

13. Erfan SMA. Immediate complication of Laparoscopic Cholecystectomy: A prospective Study of 100 Cases [Dissertation].[Dhaka]: Bangladesh College of Physicians and Surgeons; 1997.

14. Russel RCG. The Gall Bladder and Bile Duct. In: Williams NS and Bulstrode CJK editor. Bailey and Love's Short Practice of Surgery. Hodder, A member of hodder headline group; p. 1094-1100.

15. Chandler CF, Lane JS, Ferguson P, Thompson JE, Ashley SW. Prospective Evaluation of Early Versus Delayed Laparoscopic Cholecystectomy for Treatment of Acute Cholecystitis. Am Surg. 2000; 66: 896-900

16. Kolla SB, Aggarwal S, Kumar A, et al. early vs Delayed Laparoscopic Cholecystectomy for Acute cholecystitis: A Prospective Randomized Trial. Surg Endosc. 2004; 18:1323-1327. 